\title{
El bosó de Higgs
}

\author{
Jordi Nadal \\ Doctor en Física, Institut de Física d'Altes Energies (IFAE) (Bellaterra)
}

La recent descoberta del possible bosó de Higgs ha estat un èxit de la física, que hi ha dedicat l'esforç de moltes persones al llarg de molt anys. No obstant això, les més avançades teories físiques encara tenen problemes que caldrà anar resolent amb més dades $i$ segurament amb nous experiments.

Paraules clau: Model Estàndard, bosó de Higgs, massa, LHC, CERN, Peter Higgs

El passat 4 de juliol el Centre Europeu per a la Recerca Nuclear (CERN) anunciava a Ginebra (fig. 1) la detecció d'un bosó amb unes característiques molt semblants al bosó de Higgs. Un bosó és una partícula elemental a través de la qual els més bàsics constituents de la matèria interaccionen.

Aquesta troballa ha estat una gran notícia per al món científic. Però per què?

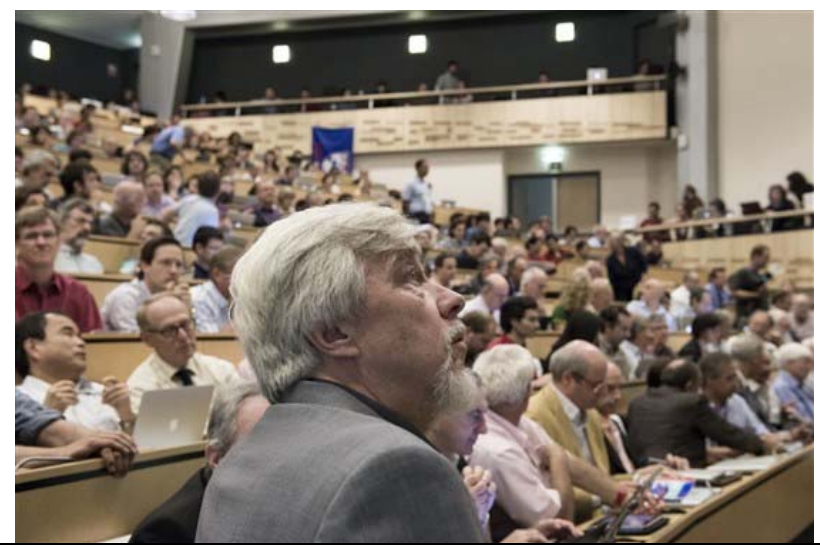

Figura 1. Anunci del descobriment del bosó de Higgs al CERN. En primer terme, el director general del CERN, Rolf Heuer. (CERN)

\section{La peça que faltava}

D'ençà que el 1897 J.J. Thomson va descobrir la primera partícula subatòmica, l'electró, la llista de partícules subatòmiques s'ha anat fent més i més
Ilarga. Cada descobriment era, és clar, una excellent notícia per al món de la ciència. Però també significava afegir complicació al món subatòmic, un món que ningú s'esperava pas que fos tan enrevessat.

Això va obligar als físics a buscar una forma d'organitzar d'alguna manera aquest aparent desori. És així com a mitjans de la dècada dels 70 s'arribà a construir un model que explica força satisfactòriament les propietats i comportament de les partícules subatòmiques. Se l'anomena Model Estàndard.

El Model Estàndard és una teoria que prediu l'existència de partícules que formen la matèria, anomenades fermions, com els electrons 0 els quarks, i partícules mitjançant les quals interacciona la matèria, els bosons.

Però aquesta teoria, tan satisfactòria en molts aspectes, tenia un gran problema tal com estava formulada al seu inici: les partícules no haurien de tenir massa! (cosa que experiments de l'època ja havien descartat).

El 1964 Peter Higgs (fig. 2) va desenvolupar un mecanisme (fig. 3) que faria que algunes partícules poguessin adquirir massa.

Però aquest mecanisme exigia una condició: l'existència d'una nova partícula que encara no s'havia observat experimentalment, l'anomenat bosó de Higgs. Segons aquesta idea, les partícules subatòmiques, com l'electró, el muó i tots els quarks adquireixen massa per la seva interacció amb el bosó de Higgs. El mateix bosó també té massa perquè interacciona amb ell mateix. 


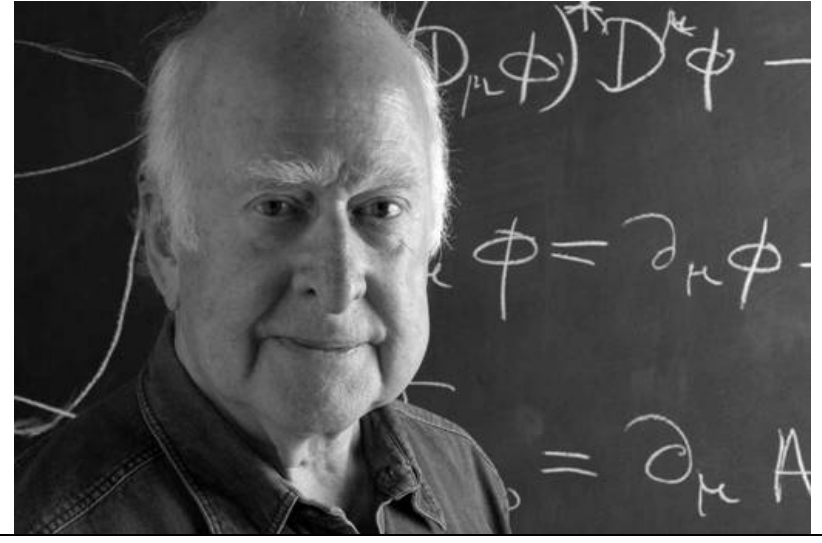

Figura 2. Peter Higgs, el 2008 davant de les seves equacions. (font)

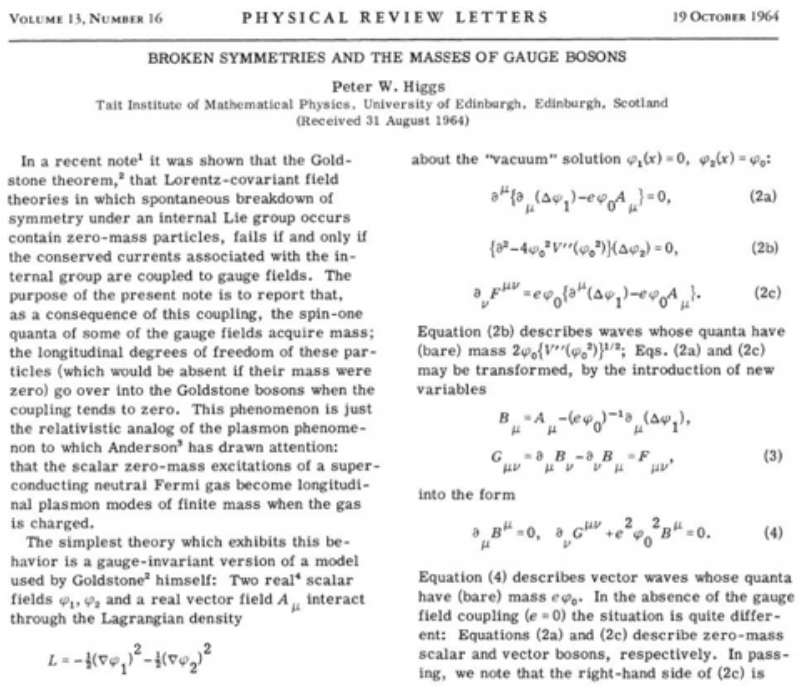

Figura 3. Article de Higgs del 1964: "Broken symmetries and the masses of gauge bosons" publicat a la revista Physical Review Letters.

Des del descobriment del neutrí tauònic l'any 2000, el bosó de Higgs era l'última peça que quedava per confirmar experimentalment dins del Model Estàndard. Sense l'existència d'aquest bosó el Model Estàndard es quedaria coix i caldria buscar una altra teoria que expliqués la natura sense un bosó de Higgs.

Aquest mecanisme -que fa que algunes partícules tinguin més massa, que unes altres o algunes no en tinguin- s'ha comparat sovint al que passa en una sala plena de periodistes. Si entra a la sala una persona famosa, els periodistes s'hi enganxaran, fent difícil que es pugui moure a través de la sala, és a dir, aquesta dificultat de moviment la podem anomenar massa. En canvi, si hi entra una persona de menys interès mediàtic la interacció serà menor $\mathrm{i}$ interaccionarà menys amb els periodis- tes. El mecanisme de Higgs explica, d'aquesta manera, que hi hagi partícules amb massa més gran, més petita, o sense.

Què passaria si no hi hagués un mecanisme que donés massa als electrons, per exemple? Doncs que l'electró no estaria lligat a l'àtom i això provocaria que els àtoms no fossin estables i tampoc la matèria ordinària. De fet, nosaltres mateixos no existiríem en un univers així!

Així, doncs, si existim és gràcies, entre moltes altres coses, al bosó de Higgs.

\section{La cerca experimental}

Un cop predita l'existència del bosó de Higgs faltava demostrar-la experimentalment.

Se saben algunes propietats d'aquesta nova partícula. Sabem que ha de ser un bosó amb spin enter nul (a diferència dels fermions, de spin fraccionari). Però la teoria no precisa quina ha de ser la seva massa i, per tant, no se sabia on buscar-la.

El rang de masses possibles per al bosó de Higgs s'ha anat estrenyent progressivament amb dades de dos acceleradors, el Tevatron de Chicago i l'LHC de Ginebra. Gràcies a que aquest últim té una energia que triplica la del Tevatron s'han pogut assolir aquests resultats molt més ràpidament. L'LHC està funcionament des de setembre del 2008, una instal.lació que ha costat 8900 milions de d'euros als 113 països que hi han participat.

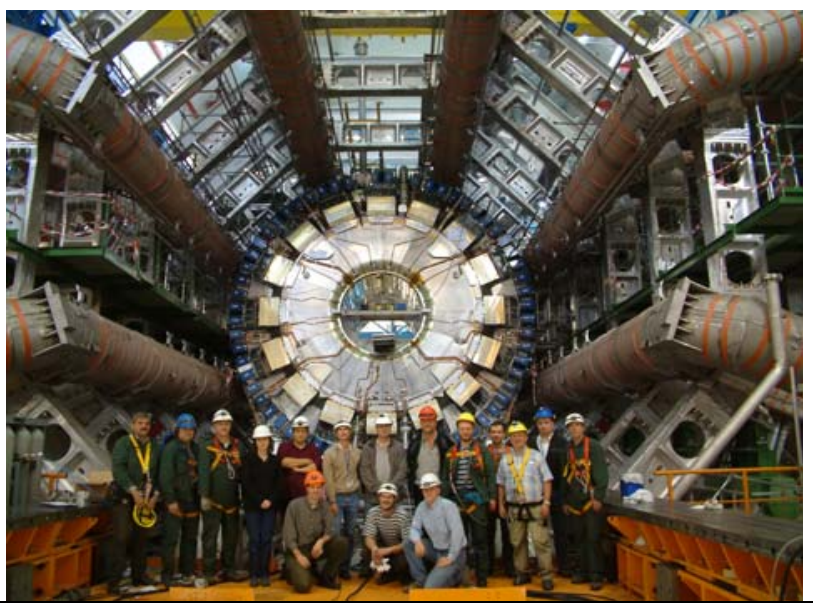

Figura 4. El detector ATLAS del CERN, durant la seva construcció el 2005. Un cop complet té una massa de 7000 tones.

Per fer-nos una idea de l'esforç humà que aquest centre suposa només direm que només un dels seus quatre detectors, ATLAS (fig. 4), on I'IFAE participa activament, compta en aquest mo- 
ment amb la col·laboració de més de 3000 físics de 176 instituts d'investigació i universitats ubicades en 38 països al voltant del món. Més de 1000 estudiants de doctorat estan involucrats tant en el seu funcionament com en l'anàlisi de les dades que produeix.

L'LHC accelera feixos de protons fins a velocitats properes a la de la llum, proporcionant actualment $4 \mathrm{TeV}$ ( $\mathrm{TeV}=10^{12}$ electró-volts) per feix (com si per accelerar un protó connectéssim en sèrie 2,7 bilions de piles d'1,5 V, que gairebé arribarien de la Terra al Sol).

Per això, quan dos protons xoquen frontalment s'allibera una energia de $8 \mathrm{TeV}$, que s'esperava que seria suficient per poder observar la formació de bosons de Higgs o, més ben dit, els seus productes de desintegració (figs. 5 i 6), ja que la vida d'aquest bosó és extremadament breu.

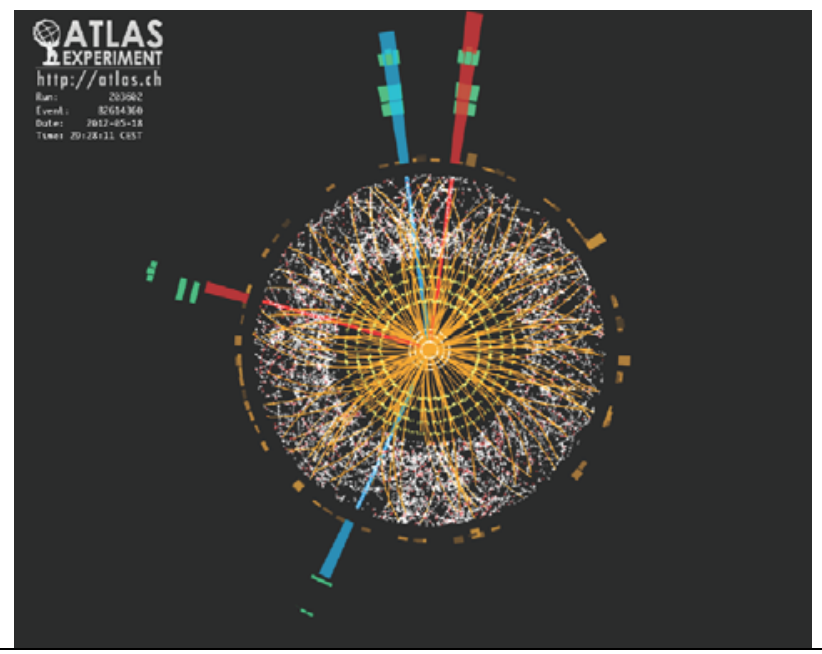

Figura 5. Possible desintegració del bosó de Higgs en quatre electrons, enregistrada per ATLAS el 2012.

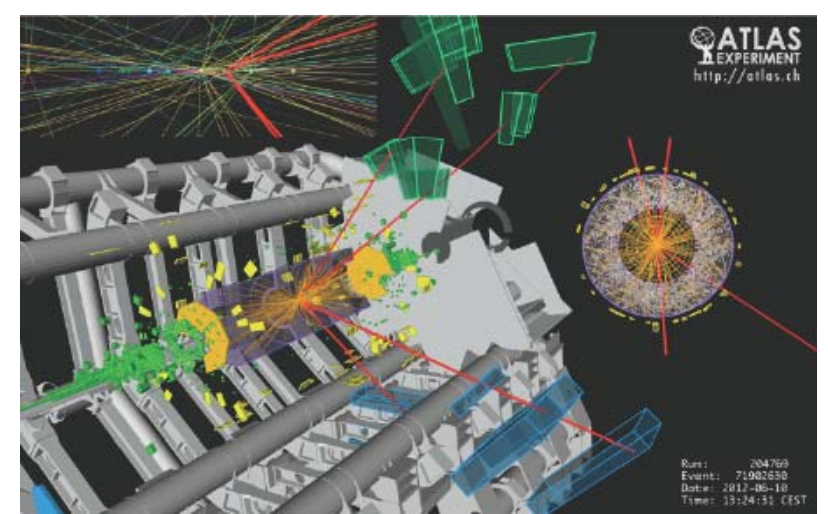

Figura 6. Possible desintegració del bosó de Higgs en quatre muons (línies vermelles), enregistrada per ATLAS el 2012.
El Model Estandard descriu perfectament els possibles tipus de desintegració del Higgs. Per això la seva cerca experimental consisteix en analitzar cada col-lisió protó-protó per descobrir-hi les partícules que podrien delatar-lo.

Pot semblar fàcil, però no ho és. Cal pensar que entre 2011 i 2012, quan s'han recollit les dades utilitzades, s'han produït $10^{15}$ col-lisions (mil bilions!) que ha calgut analitzar ja que el Higgs només apareix en una d'entre 10000 milions de col-lisions.

Les dades recollides ocupen 3000 teraoctets, equivalents a un pila de CD de 7 quilòmetres d'alta.

Evidentment, ha fet falta una enorme capacitat de procés de dades per separar el gra de la palla, consistent en la utilització en xarxa de 170 installacions de processament de dades en 36 països d'arreu del món.

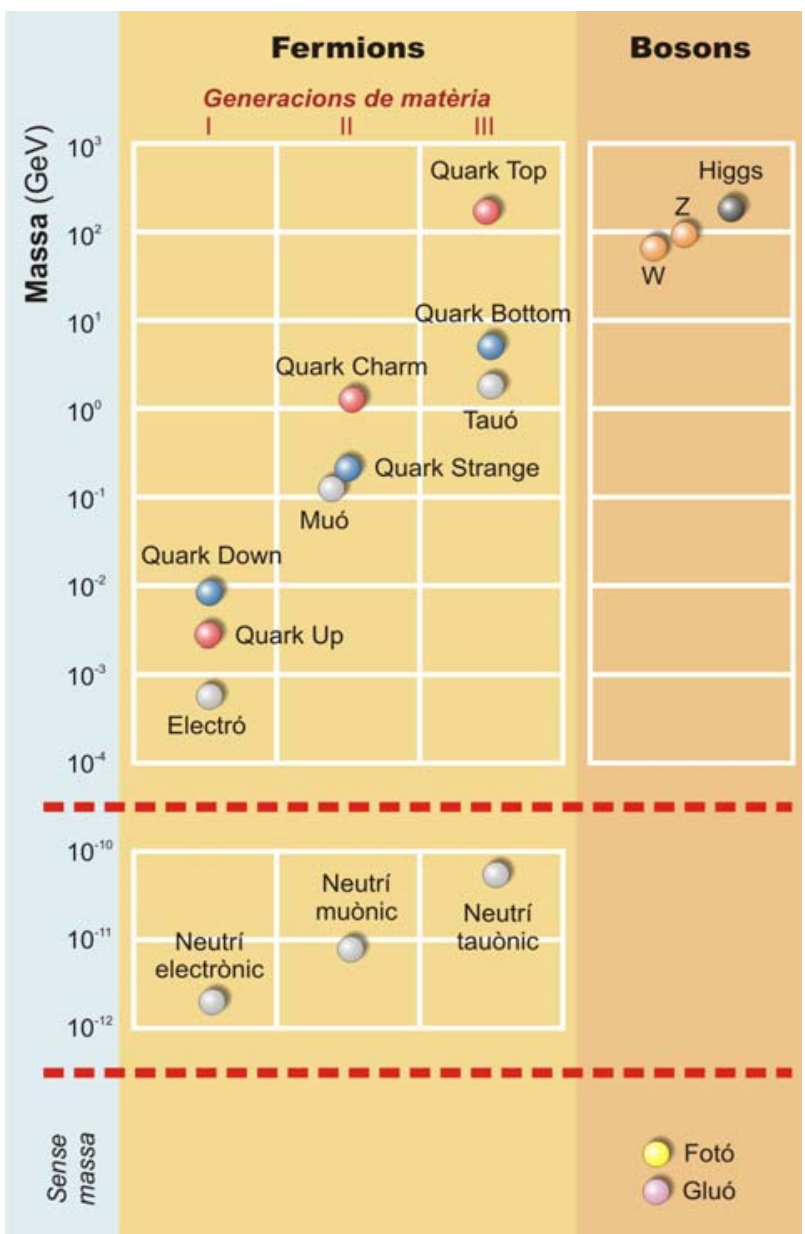

Figura 7. Massa de les diverses partícules elementals. El bosó de Higgs té una de les masses més elevades. 


\section{Els resultats}

En física de partícules no es dóna per descoberta una nova partícula fins que s'està un 99,9997\% segurs que s'ha trobat. Això vol dir, que hi ha una probabilitat d'error d'un contra 550 milions.

Amb les dades que ja tenim en mà, hem pogut mesurar la massa del bosó de Higgs, que ha resultat ser propera a $126 \mathrm{GeV} / \mathrm{c}^{2}$. Las segona partícula elemental més "pesada" després del quark top (fig. 7).

\section{L'èxit llargament esperat de Peter Higgs}

Peter Higgs (fig. 8) és actualment professor emèrit de la Universitat d'Edimburg. 48 anys després de fer la seva predicció de l'existència d'un camp i un bosó, l'ha pogut veure confirmada per l'experimentació. Ha esdevingut una personalitat coneguda (fig. 9) i un candidat ferm al premi Nobel.

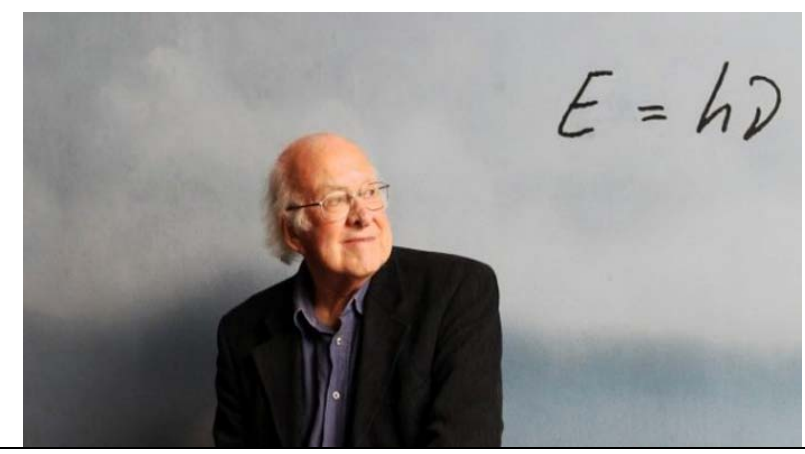

Figura 8. El professor Higgs en la seva recent visita a Barcelona el 6 de novembre del 2012.

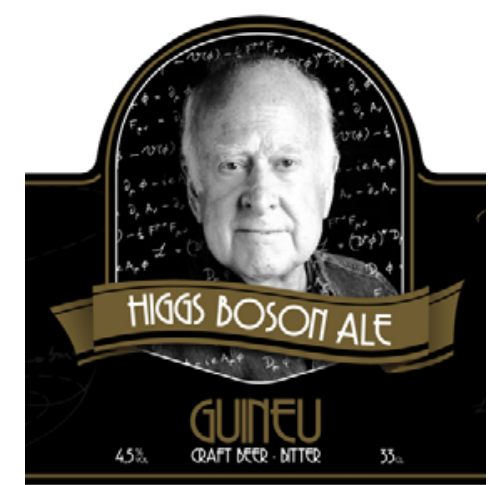

Figura 9. Una marca catalana de cervesa artesana n'ha comercialitzat una en homenatge a Higgs i el seu bosó.

\section{Perspectives de futur}

Però l'èxit innegable que suposa la confirmació experimental de l'existència d'aquest bosó no resol pas, ni de bon tros, els problemes que encara arrossega el Model Estàndard:

- Els neutrins no haurien de tenir massa, però se sap que en tenen, encara que és molt petita.

- Estudiant la dinàmica de les galàxies s'ha trobat que la matèria ordinària suposa amb prou feines una sisena part de tota la matèria que hi ha a l'univers. La resta s'anomena matèria fosca i no té encara cap explicació acceptada.

- Encara més, l'acceleració detectada en l'expansió de l'univers ens ha mostrat que la matèria ordinària juntament amb la fosca és poc més d'una quarta part del contingut de l'univers, ja que la resta és l'anomenada energia fosca, la naturalesa de la qual també està per aclarir.

- Un dels reptes d'Einstein: la unificació de totes les forces de la natura no s'ha acabat d'aconseguir. Encara resta la força gravitatòria.

Per tot això s'estan buscant alternatives al Model Estàndard, de forma que l'incorporin per aprofitar els seus èxits, però al mateix temps el superin per explicar el que resta per explicar.

Aquests són alguns dels camps de recerca per on s'intenta avançar-hi:

- A partir d'ara, amb l'LHC es seguiran obtenint dades amb la finalitat d'anar precisant les propietats de la partícula trobada. Un dels interrogants és aclarir si el que s'ha trobat és efectivament el bosó de Higgs. També si hi ha un sol tipus de Higgs o n'hi ha de diferents menes. Segons quina sigui la resposta podria aportar una explicació satisfactòria a la inflació còsmica, el creixement desmesurat de l'univers en els seus primers instants, ara per ara sense explicació.

- També s'explora la possibilitat de l'existència de dimensions extres, com fa per exemple la teoria de cordes. Suposa que cada partícula està feta de vibracions en diferents dimensions. És una teoria molt difícil de provar experimentalment, ja que queda fora de l'abast de la nostra tecnologia actual. 
- Hi ha grups molt interessats per les teories basades en la supersimetria. La teoria es tornaria més consistent si a més a més de les partícules conegudes hi hagués unes altres partícules com elles però amb més massa (fig. 10).

A principis del 2013 I'LHC s'aturarà per fer-hi ajustaments que permetin passar de funcionar als 8 $\mathrm{TeV}$ actuals a 10 o $14 \mathrm{TeV}$, que és el màxim que permet el seu disseny. La nova posada en funcionament està prevista cap a finals dels 2014.

Serà una nova oportunitat per a noves descobertes.

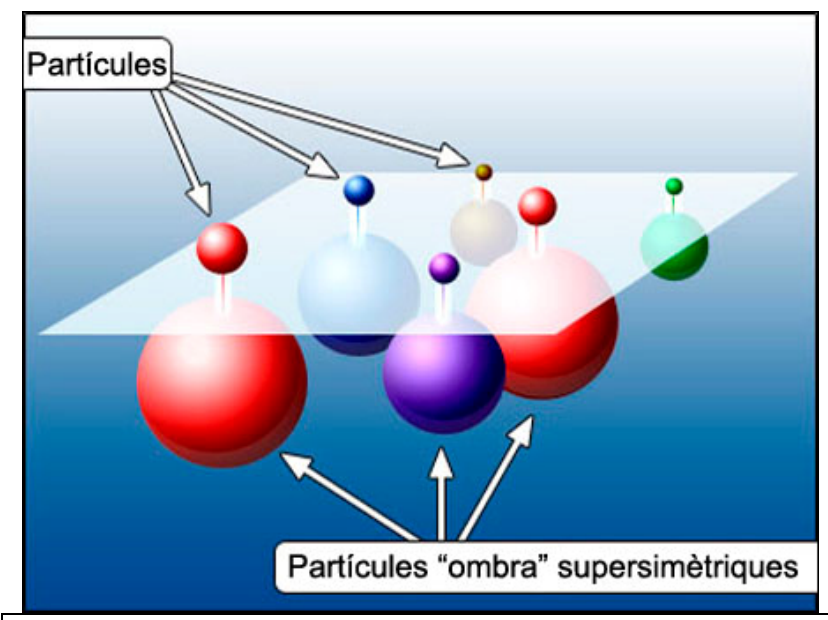

Figura 10. Relació entre algunes partícules i les seves corresponents supersimètriques. (font) 